\title{
Obesity in rural mothers in the north of Iran (southeast of caspian sea): an epidemiologic study
}

\begin{abstract}
Background: Obesity is the main health problem in worldwide.

Objectives: The aim of this study is the evaluation of obesity among women in a rural area in two districts in Golestan Province (north of Iran) in 2013.

Material and methods: This was a cross-sectional study with 2545 (Gorgan=1106 and Aq-Qala=1439) women participated. Interviewers recorded the data using the questionnaire and subjects were weighed on scales and had their height by measure. Economic status was categorized based on 16 facility items considered necessary for modern-day life (Low $>=6$, Moderate=7-11 and Good=12-16). Obesity defined based on Body Mass Index (BMI) that classified by World Health Organization. SPSS 18.0 software was used for statistical data analysis and P.value under 0.05 included significations.

Results: Body Mass Index (BMI) in ranges of (25-29.9), (30-39.9) and ( $>=40)$ was observed in $33.1 \%, 19.5 \%$ and $0.7 \%$ of the subject, respectively. The frequency of BMI over 25 among Gorgan and Aq-Qala mothers was $54.1 \%$ and $52.8 \%$, respectively and statistical differences was not significant. The prevalence of obesity among poor, middle and good economic status was $14.1 \%, 19.6 \%$ and $27.9 \%$, respectively, with significant difference $(\mathrm{P}=0.001)$.
\end{abstract}

Conclusion: Obesity is a common health problem among women in the rural areas of Gorgan and Aq-Qala and it was positively associated with economic status.
Volume 2 Issue I - 2015

\author{
Gholamreza Veghari \\ Department of Nutrition, Golestan University of Medical \\ Sciences, Iran
}

\begin{abstract}
Correspondence: Gholamreza Veghari, Ischemic Disorders Research Center-School of Medicine, Golestan University of Medical Sciences, Gorgan, Iran, Tel 00989/ 1377/432, Email grveghari@yahoo.com
\end{abstract}

Received: October 29, 2014 | Published: January 02, 2015

Keywords: obesity, economic status, mother, Iran

\begin{abstract}
Abbreviations: BMI, body mass index; SD, standard deviation
\section{Introduction}

Obesity, a cardiovascular risk factor has remained as a main health problem and substantially increased during the last decade in many countries. ${ }^{1}$ Imbalance between taking food and consuming calorie leads to overweight and obesity. ${ }^{2}$ Some factors are responsible for the weigh increase in body. The metabolic factors such as leptin, life style and low physical activities have been known the important factors for overweight and obesity. ${ }^{3}$ In the Third National Surveillance of Risk Factors of Non-communicable Disease, the overall prevalence of obesity was reported $22.3 \%$ in Iran and in this survey obesity was much more common in females and in urban residents. ${ }^{4}$ Studies in the north of Iran ${ }^{5,6}$ approved the obesity as a major health problem in this area.
\end{abstract}

In regard to the rule of obesity and the changing of the life-span, it seems necessary to recognize the people at risk and the pre-existing for this abnormality. Among the various methods for the determination of obesity and overweight, BMI (body mass index) is common more than others and is used for the determination of obesity degrees. ${ }^{7}$

Of 1.7 million populations in the Golestan province (north of Iran and southeast of Caspian Sea), 586640 person are living in Gorgan and Aq-Qala districts. The proportion of rural residence in two areas is $25.6 \%$ and $69.3 \%$, respectively. The main job in rural area is agriculture and different ethnic groups such as Turkman, Fars-native and Sisstani are living in this region. ${ }^{8}$
Due to the restriction in performing of epidemiological projects, the study on obesity and its related factors is scarce in the north of Iran, up till now; therefore it was necessary to design a research project to determine the obesity status and some related factors. This idea was carried out in a study among the rural mothers in two capital districts (Gorgan and Aq-Qala) in the north of Iran.

\section{Material and methods}

\section{Study designs and subjects}

In a descriptive and cross-sectional study, by a component type sampling (cluster and simple sampling), 2545 mothers of under-five years children were chosen in 21 villages around Gorgan and Aq-Qala in the north of Iran. BMI was calculated as weight $(\mathrm{kg}) /$ height $\left(\mathrm{m}^{2}\right)$. Those with a BMI of $25.0-29.9 \mathrm{~kg} / \mathrm{m}^{2}$ were classified as overweight, whilst those with a $B M I \geq 30.0 \mathrm{~kg} / \mathrm{m}^{2}$ were classified as obese and $\mathrm{BMI} \geq 40$ classified as pathologic obese. ${ }^{1}$

\section{Data collection}

Using a questionnaire, the data were recorded by 21 trained interviewers. Economic status was categorized based on 16 facilities possession considered necessary for modern-day life. In that way, the economic status was classified as follows: low $\geq 6$, moderate $=7-11$, and good=12-16.

Weight was measured without shoes and clothing using a balance and height was measured using a tape meter while the participants were standing on their feet. Weight and height recorded nearest $0.5 \mathrm{~kg}$ and $0.5 \mathrm{~cm}$, respectively. 


\section{Data analysis}

SPSS 18.0 software was used for statistical data analysis. We used the t.test and ANOVA for comparing of means and $\chi^{2}$ test for comparing of quantities groups. P value under 0.05 included significations. Pregnant women and subjects, who were not interested to contribute, have been excluded from this study. This study approved by Ethical Research Committee of Golestan University of Medical Sciences (GP-35-1112). Verbal informed consent was received from all cases.

\section{Results}

The mean \pm standard deviation (SD) of age was $28.0 \pm 5.7$ years. The mean \pm SD of BMI was $27.2 \pm 5.2$ and $28.4 \pm 6.1 \mathrm{~kg} / \mathrm{m}^{2}$ in Gorgan and Aq-Qala districts, respectively. Poor economic status was significantly more in Gorgan than in Aq-Qala districts $(\mathrm{P}=0.001)$ (Table 1).

As a whole, overweight and obesity was seen in $33.1 \%$ and $20.2 \%$, respectively. The overweight and obesity in Gorgan women (54.1\%) was more than in Aq-Qala women (52.8\%), but statistical differences was not significant (Table 2).
According to our economic status definition, the mean of BMI increased with improving of economic status. The positive association was seen between economic status and obesity $(\mathrm{P}=0.001)$ (Table 3$)$.

Table I Characteristics of study's subjects $(\mathrm{No}=2545)$

\begin{tabular}{llll}
\hline & Gorgan & Aq-Qala & P. value \\
\hline Frequency N (\%) & $1106(43.5)$ & $1439(56.5)$ & \\
Age -year (Mean \pm SD) & $27.4 \pm 5.2$ & $28.4 \pm 6.1$ & 0.001 \\
BMI -kg/m² (Mean \pm SD) & $26.2 \pm 5.3$ & $25.8 \pm 5.1$ & 0.060 \\
\hline Economic status N (\%) & & & \\
\hline Poor & $320(29)$ & $274(19.1)$ & 0.001 \\
Middle & $545(49.5)$ & $783(54.7)$ & 0.010 \\
Good & $237(21.5)$ & $375(26.2)$ & 0.001 \\
\hline
\end{tabular}

Table 2 Distribution of BMI and obesity among mothers in Gorgan and Aq-Qala

\begin{tabular}{|c|c|c|c|c|c|c|c|}
\hline \multirow{2}{*}{ District } & \multirow{2}{*}{$\mathbf{N}$} & \multicolumn{6}{|l|}{ BMI distribution } \\
\hline & & Mean (SD) $\mathrm{Kg} / \mathrm{m}^{2}$ & Low $\mathbf{N}(\%)$ & Normal N (\%) & Overweight N (\%) & Obesity N (\%) & Pathologic obesity N (\%) \\
\hline Gorgan & 1106 & $26.2(5.3)$ & $47(4.2)$ & $46 I(4 I .7)$ & $368(33.3)$ & $22 I(20)$ & $9(0.8)$ \\
\hline Aq-Qala & 1439 & $25.8(5.1)$ & $75(5.2)$ & $604(42.0)$ & $474(32.9)$ & $276(\mid 9.2)$ & $10(0.7)$ \\
\hline Total & 2545 & $25.9(5.2)$ & $122(4.8)$ & $1065(4 \mid .8)$ & $842(33.1)$ & $497(19.5)$ & $19(0.7)$ \\
\hline$P$ value & & 0.06 & 0.239 & 0.882 & 0.859 & 0.613 & 0.729 \\
\hline
\end{tabular}

Table 3 Distribution of BMI and obesity status based on economic status

\begin{tabular}{|c|c|c|c|c|c|c|c|}
\hline \multirow{2}{*}{$\begin{array}{l}\text { Economic } \\
\text { status }\end{array}$} & \multirow{2}{*}{$\mathbf{N}$} & \multicolumn{6}{|l|}{ BMI distribution } \\
\hline & & Mean (SD) Kg/m² & Low N (\%) & Normal N (\%) & Overweight N (\%) & Obesity N (\%) & Pathologic obesity N (\%) \\
\hline Poor & 594 & $24.9(5.2)$ & $32(5.4)$ & $312(52.5)$ & $166(27.9)$ & $78(\mid 3.1)$ & $6(1.0)$ \\
\hline Middle & 1328 & $25.9(5.1)$ & $68(5.1)$ & $540(40.7)$ & $460(34.6)$ & $255(19.2)$ & $5(0.4)$ \\
\hline Good & 612 & $27 . I(5.2)$ & $22(3.6)$ & 206(33.7) & $213(34.8)$ & $163(26.6)$ & $8(1.3)$ \\
\hline Total & 2534 & $25.9(5.2)$ & $122(4.8)$ & $1058(41.8)$ & $839(33.1)$ & $496(19.6)$ & $19(0.7)$ \\
\hline$P$ value & & 0.001 & 0.261 & 0.001 & 0.009 & 0.001 & 0.061 \\
\hline
\end{tabular}

II subjects missed from the study.

\section{Discussion}

The finding of this study showed that obesity and overweight are the main health problem among the rural women in Gorgan and Aq-Qala. Generally, one to five of women was obese and one to two hundred of them was pathologic obese, who needed to be treated. However the obesity was common more in Gorgan than Aq-Qala. Based on studies in the north of Iran the prevalence of obesity was $16.4 \%$ in rural women in Gorgan, ${ }^{9} 28.6 \%$ in women in whole of Golestan province ${ }^{5}$ and $33.3 \%$ in rural women in Golestan province. ${ }^{10}$ The obesity among women in Bahrain, ${ }^{11}$ Saudi Arabia, ${ }^{10}$ Lebanon ${ }^{12}$ and in Eastern Mediterranean region ${ }^{13}$ has been prevalent $21.2 \%$, $26.6 \%, 18.8 \%$ and $35-75 \%$, respectively.

The prevalence and pattern of obesity is considerably dissimilar among countries. The prevalence rate of obesity ranges from as low as $\leq 5 \%$ in China, Japan, and some region in Africa to as high as $\geq 75 \%$ in urban Samoa. However, even in countries such as China, the prevalence of obesity is almost $20 \%$ in some cities, the overall prevalence of obesity is relatively low. ${ }^{14}$ The pattern of obesity in the family is dependant on genetic, but genetic factor required a proper and special environment. The genetic factors responsible for the obesity reveal itself when they are placed in proper situation. ${ }^{15}$

Our study was indicated that the prevalence of obesity and overweight among rural women in Gorgan and Aq-Qala (north of Iran) are high. In present study a meaningful direct correlation between the economic status and obesity has been investigated. If this trend is continued in future, it is expected that we will face much more difficulty due to side- effect of obesity and overweight in the north of Iran. The association between economic status and obesity, has been approved by others, ${ }^{6,9,12,13}$ as like as our study. In Iranian northern schoolchildren, the risk of obesity in good economic families was seen 2.2 times more than in poor economic families. ${ }^{16}$

The pattern of obesity in the two districts is not significant while economic status is a risk factor for obesity. Regards to constitute the dominant ethnic of these districts are different and most of people in 
Aq-Qala are in Turkman ethnic group, it seems environmental more than genetic factors play effective roles in these differences. In family education, mothers play an important task in forming children's mind in how much and how many times to eat and which nutrient to choose, therefore consequently mothers are the symbols of their children in this regard. ${ }^{17}$

Although in present study, the single women and mothers who did not have children less than five years, were not covered, but the results of this research may be extended to the most of women in fertility ages in the rural area in the north of Iran. Besides we didn't have ethnicity differences and food behavior variation in our study. In addition, we did not provide a proper statistical test to consider the design effect caused by cluster sampling. They are our limiting study.

\section{Conclusion}

Half of mothers in rural area in Gorgan and Aq-Qala (north of Iran) suffer from overweight and obesity and economic status is a risk factor for them. The prevalence of obesity is no differences between Gorgan and Aq-Qala. We recommend establishing a proper nutritional training for mothers, as anticipatory measures to combat obesity in the family, and the consequent benefit of these measures which is given to the public health in the society.

\section{Acknowledgements}

The author would like to thank the medical and administrative staff in the deputy of health for their valuable assistance during the field work and the Vic-chancellor of Research and Technology in Golestan University of Medical Sciences for financial support of this study. We would like to thank Habibeh Moradian for editing the paper.

\section{Conflict of interest}

The author declares no conflict of interest.

\section{References}

1. World Health Organization. Obesity: Prevention and managing the global epidemic. Switzerland: World Health Organization; 2000. 252 p.

2. Laqnatra I. Nutrition for weight management. In: Mahan lk, Raymond JL, Escott-Stump, editors. Krauses Food, nutrition and Diet therapy. 13th ed. USA: W.B. Saunders Co; 2012. p. 486- 516.
3. Auwerx J, Staels B. Leptin. Lancet. 1998;351(9104):737-742.

4. Esteghamati A, Meysamie A, Khalilzadeh $\mathrm{O}$, et al. Third nationa surveillance of risk factors of non-communicable diseases in Iran: methods and results on prevalence of diabetes, hypertension, obesity, central obesity, and dyslipidemia. BMC Public Health. 2009;9:167.

5. Veghari G, Sedaghat M, Joshaghani H, et al. Obesity in the north of Iran (South-East of the Caspian Sea). Bangladesh Med Res Counc Bull. 2010;36(3):100-103.

6. Veghari GR, Mansourian AR. Obesity among mothers in rural GolestanIran (south east of Caspian Sea). Iranian J Publ Health. 2007;36(3):7176

7. Licata G, Argano C, Di Chiara T, et al. Obesity: a main factor of metabolic syndrome? Panminerva Med. 2006;48(2):77-85.

8. http://www.amar.org.ir/Portals/1/Iran/census-2.pdf

9. Al-Nuaim AA, Bamgboye EA, al-Rubeaan KA, et al. Overweight and obesity in Saudi Arabian adult population, role of socio-demographic variables. J Community Health. 1997;22(3):211-223.

10. Veghari G, Sedaghat M, Joshaghani H, et al. The Prevalence of Obesity and its Related Risk Factor in the North of Iran in 2006. J Res Health Sci. 2010;10(2):116-121.

11. Musaiger AO, Al-Mannai MA. Weight, height, body mass index and prevalence of obesity among the adult population in Bahrain. Ann Hum Biol. 2001;28(3):346-350.

12. Sibai AM, Hwalla N, Adra N, et al. Prevalence of and covariates of obesity in Labanon: finding from the first epidemiological study. Obes Res. 2003;11(11):1353-1361.

13. Musaiger AO. Overweight and obesity in the Eastern Mediterranean Region: can we control it? East Mediterr Health J. 2004;10(6):789-793.

14. World Health Organization. Global strategies on diet, physical activity, and health. Switzerland: World Health Organization; 2006. 30 p.

15. Bouchard C, Perusse L. Heredity and body fat. Annu Rev Nutr. $1998 ; 8: 259-277$.

16. Veghari G. Prevalence of overweight obesity and socioeconomic related factors among Iranian Northern School children. J Biologi Sci. 2011;11(8):487-491.

17. Fisher JO, Birch LL. Restricting access to foods and children eating. Appetite. 1999;32(3):405-419. 